\title{
Mucoproteína versus alfa-1-glicoproteína ácida: 0 que quantificar?
}

\section{Mucoprotein versus alpha-1-acid glycoprotein: what should be measured?}

\author{
Geraldo Picheth ${ }^{1}$ \\ Paula L. Bresolin ${ }^{2}$ \\ Osmar Pereira Jr. ${ }^{3}$ \\ Maria Cristina G. Jaworski \\ Celso M. Santos ${ }^{2}$ \\ Adriana P. Pinto ${ }^{2}$ \\ Marileia Scartezini ${ }^{1}$ \\ Vânia M. Alcântara' \\ Cyntia M.T. Fadel-Picheth ${ }^{1}$
}

\section{unitermos resumo}

Mucoproteina

Orosomucóide

Alfa-1-glicoproteina ácida
A quantificação sérica da alfa-1-glicoproteína (GPA) ácida é útil no diagnóstico e no acompanhamento dos processos agudos resultantes de múltiplas causas. Esta proteína também pode ser estimada pela quantificação da mucoproteína (Muco), ensaio que reflete as glicoproteínas com elevado teor de açúcar, entre as quais a GPA é majoritária. O objetivo deste trabalho é verificar a correlação e a performance analítica das determinações de mucoproteína (Muco) e alfa-1-glicoproteína ácida (GPA), propondo uma equação de regressão linear. Amostras de soros de 540 pacientes, com idades entre 10 e 79 anos (média de 34,6), predominando mulheres $(71,3 \%)$, foram analisadas simultaneamente para Muco (Winzler, manual com reagentes próprios) e GPA (imunoturbidimetria automatizada, Roche; Cobas mira). A análise de regressão, fixando a Muco como variável dependente, apresentou Muco (mg/dl em tirosina $)=0,031 \times \mathrm{GPA}(\mathrm{mg} / \mathrm{dl})+0,8(r=0,91)$; e, fixando o intercepto em zero, Muco = $0,039 \times$ GPA $(r=0,98)$. A imprecisão interensaio foi de $23,4 \%$ e 5,2\% (coeficiente de variação), respectivamente, para Muco e GPA. Conclusão: a elevada variabilidade analítica da quantificação da mucoproteína pelo método de Winzler recomenda que este ensaio seja substituído pela dosagem da alfa-1-glicoproteína ácida. Quando necessário, recomendamos estimar a mucoproteína, quantificando a alfa-1-glicoproteína ácida com ensaios de mesmo desempenho que o do utilizado neste trabalho, e usar a equação de regressão AGP $(\mathrm{mg} / \mathrm{dl}) \mathrm{x}$ $0,039=$ Muco $(\mathrm{mg} / \mathrm{dl}$ em tirosina $)$.

\section{abstract}

The alpha-1-acid glycoprotein (AGP, orosomucoid) serum measurement is useful in the diagnosis and management of acute processes of multiple causes. This protein can also be estimated by measuring the mucoprotein (Muco) that reflects the serum glycoproteins with high levels of sugars, in which than AGP is the principal component. The analytical performance between Muco and AGP was analyzed and a linear regression equation was proposed in this study. Samples from

540 patients between the ages of 10 and 79 years, averaged 34.6, being most of then women

(71.3\%), were analyzed simultaneously for Muco (Winzler manual procedure with in house reagents) and AGP (immunoturbidimetry, Roche, automated in Cobas mira). The regression equation considering Muco as a dependent variable showed: Muco ( $\mathrm{mg} / \mathrm{dL}$ Tyrosine $)=0.031 \mathrm{x}$

GPA $(\mathrm{mg} / \mathrm{dL})+0.8(r=0.91)$, and fixing the intercept to zero showed Muco $=0.039 \times \mathrm{GPA}$ ( $r=0.98$ ). In the imprecision studies (inter-run, coefficient of variation) $23.4 \%$ and $5.2 \%$ were found for Muco and AGP, respectively. Conclusion: the determination of serum mucoprotein is a highly imprecise assay that must be substituted by alpha-1-acid glycoprotein measurement. When necessary, we recommend the estimate of mucoprotein values, measuring AGP, with assays with same performances as we did in this paper, and using the regression equation $A G P(\mathrm{mg} / \mathrm{dL}) \mathrm{x}$ $0.039=$ Muco ( $\mathrm{mg} / \mathrm{dL}$ in Tyrosine).

\section{key words}

Mucoprotein

Orosomucoid

Alpha-1-acid glycoprotein
1. Professor do Departamento de Patologia Médica, Universidade Federal do Paraná (UFPR) 2. Farmacêutico-bioquímico do Laboratório Frischmann Aisengart, Curitiba-PR.

3. Farmacêutico-bioquímico do Laboratório do Hospital de Clínicas, UFPR.

Trabalho apresentado nas formas de resumo e pôster durante $034^{\circ}$ Congresso da Sociedade Brasileira de Patologia Clínica, realizado em Florianópolis, no ano 2000. 


\section{Introdução}

O processo inflamatório agudo, decorrente de infecções, danos teciduais ou proveniente de outros estímulos, induz o aumento da concentração de várias proteínas séricas, designadas como "proteínas de fase aguda" $(1,4)$. A quantificação destes marcadores no soro pode ser útil na detecção do processo agudo, bem como no seu monitoramento $(2,8,12)$.

Uma fração das glicoproteínas séricas, ricas em polissacarídeos ácidos, foi designada por Winzler et al., no início dos anos 50, como "mucoproteína", sendo uma das primeiras frações a serem isoladas e relacionadas como proteínas de fase aguda $(3,18)$. A denominação deriva da característica viscosa ou "limosa" (mucóide, do grego mýxa = viscoso) apresentada por esta proteína durante seu processo de purificação (18) e justifica também o nome "seromucóide" dado a esta fração (5). O próprio Winzler recomenda substituir a designação "mucoproteína sérica" por "seromucóide". A elevada concentração de carboidratos, com proporções marcantes de açúcares ácidos, confere à fração mucoproteína uma resistência maior à desnaturação por ácidos, característica utilizada no processo de separação desta fração das demais proteínas do soro.

Winzler (17), na metade dos anos 50, desenvolveu um procedimento que se tornou amplamente utilizado para a quantificação da mucoproteína. Este método baseia-se na separação da mucoproteína por precipitação seletiva com ácido perclórico e posterior quantificação colorimétrica baseada no teor de tirosina presente na fração isolada. As fases deste procedimento analítico, na essência idêntico ao realizado nos laboratórios clínicos atuais, estão sumarizadas na Figura 1. A compreensão deste princípio analítico é importante na avaliação da qualidade e da confiabilidade dos resultados obtidos com esta técnica.

A alfa-1-glicoproteína ácida (GPA) é constituída de 181 resíduos de aminoácidos e apresenta massa molecular de aproximadamente $41 \mathrm{kDa}$ a $43 \mathrm{kDa}$. Cerca de $45 \%$ deste peso são devidos a carboidratos, com hexose, hexosamina e ácido siálico presentes em iguais proporções $(3,4)$. Esta proteína, também conhecida como "orosomucóide", é o componente quantitativamente mais importante da fração mucoproteína presente no soro $(3,5)$, sendo a porção carboidrato da molécula relacionada a processos de modulação do sistema imune (14). Os procedimentos analíticos em maior uso para a quantificação da GPA são a turbidimetria e a nefelometria, automatizadas, realizadas

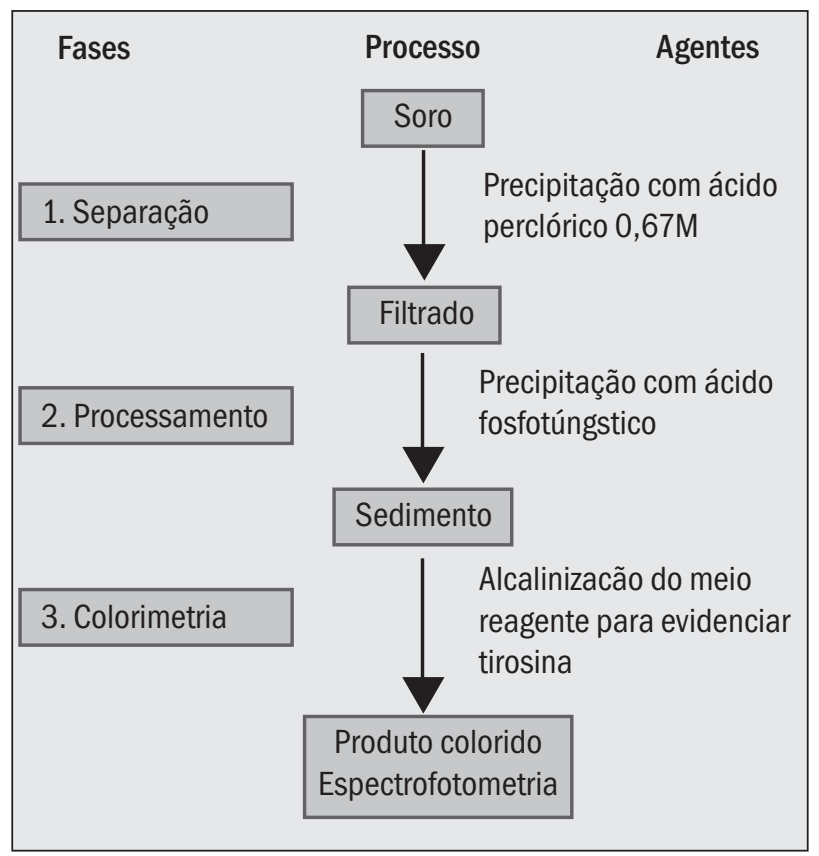

Figura 1 - Fases do procedimento analítico para quantificacão das mucoproteínas pelo método de Winzler $(10,11)$

na presença de anticorpos específicos $(2,4)$. As excelentes reprodutibilidade e confiabilidade destes procedimentos os têm recomendado para substituir a determinação da mucoproteína $(7,16)$.

Neste trabalho, estudamos a precisão analítica das determinações de mucoproteína e alfa-1-glicoproteína ácida e, através de análises de regressão linear, propomos equações para estimar a mucoproteína através da quantificação da alfa-1-glicoproteína ácida.

\section{Materiais e métodos}

\section{Amostra}

Soros de 540 pacientes com idades entre 10 e 79 anos (média de 34,6), predominando mulheres (71,3\%), foram analisados simultaneamente para mucoproteína (média e desvio padrão de 3,74 $\pm 1,21$ e amplitude de variação de 1,33mg/dl a 9,8mg/dl em tirosina) e alfa-1-glicoproteína ácida (média e desvio padrão de 93,2 $\pm 34,3$ e amplitude de variação de $38,5 \mathrm{mg} / \mathrm{dl}$ a $264 \mathrm{mg} / \mathrm{dl}$ ).

\section{Procedimentos analíticos}

A mucoproteína foi quantificada pelo método de Winzler, com reagentes próprios, conforme descrito em Moura et al. (10) e Nogueira et al. (11), sendo os resultados expressos em mg/dl em tirosina. A alfa-1-glicoproteína ácida foi quantificada por imunoturbidimetria utilizando 
reagentes, calibradores e controles Roche, em sistema automatizado Cobas mira (Roche), com resultados expressos em $\mathrm{mg} / \mathrm{dl}$.

\section{Imprecisão interensaio}

Um pool de soros, isento de hemólise, lipemia e icterícia, foi distribuído em alíquotas e mantido em freezer $\left(-20^{\circ} \mathrm{C}\right)$. Alíquotas descongeladas apenas uma vez foram ensaiadas para mucoproteína (Muco) e alfa-1-glicoproteína ácida durante 15 dias, dentro da rotina.

\section{Procedimentos estatísticos}

Análises estatísticas de correlação e regressão linear foram realizadas com o programa Statistica 5.0 para Windows, Statsoft (15).

\section{Resultados}

Os resultados da imprecisão analítica encontram-se na Tabela.

As Figuras 2 e 3 mostram as análises de regressão linear obtidas com a amostra em estudo, respectivamente, com intercepto e quando este é forçado a zero. A mucoproteína foi considerada variável-dependente. O coeficiente de correlação foi $\geq 0,91(p<0,00001)$ para as duas análises.

\section{Discussão}

A quantificação da mucoproteína sérica (muco) pelo método de Winzler não é citada em publicações internacionais há mais de duas décadas, tendo sido substituída amplamente pela quantificação da alfa-1-glicoproteína ácida (GPA) em países de primeiro mundo.

O custo expressivamente menor dos reagentes por teste para a determinação da Muco (cerca de $\mathrm{R} \$ 0,45$ Bioclin, Labtest), em comparação com o custo da dosagem da GPA (entre R $\$ 0,80$ e R $\$ 6,25$ - Ames, Aptec, Bioclin, Roche), possivelmente contribui para a manutenção da Muco na rotina laboratorial.

Diversas fontes de possível variação analítica estão relacionadas à determinação da Muco pelo método em estudo, as quais podem ser alocadas conforme a fase do procedimento metodológico (Figura 1). Na fase de separação, o processo é temperatura-dependente, sendo críticas a concentração do ácido perclórico e sua adição lenta e sob agitação à amostra de soro. Na fase de proces-

\begin{tabular}{lcc} 
& \multicolumn{2}{l}{$\begin{array}{l}\text { Imprecisão interensaio para muco- } \\
\text { proteina (Muco) e alfa-1-glicopro- } \\
\text { Tabelina ácida (GPA) }\end{array}$} \\
\hline $\mathrm{N}=15$ & Muco & $\mathrm{GPA}$ \\
& $(\mathrm{mg} / \mathrm{dl}$ em tirosina) & $(\mathrm{mg} / \mathrm{dl})$ \\
Média & 2,95 & 79,5 \\
Desvio padrão & 0,69 & 4,13 \\
CV (\%) & 23,4 & 5,2 \\
\hline
\end{tabular}

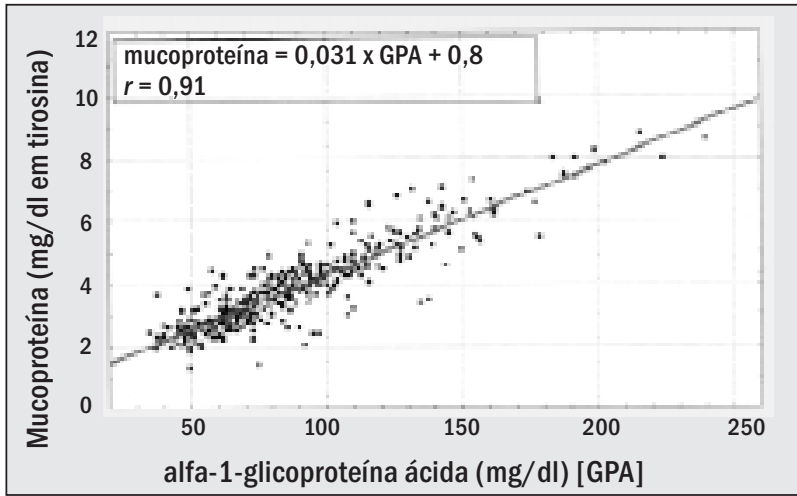

Figura 2 - Análise de regressão linear entre alfa-1-glicoproteína ácida (GPA) e mucoproteína expressa em tirosina. 0 coeficiente de correlação (r) e a equação de regressão encontram-se em destaque

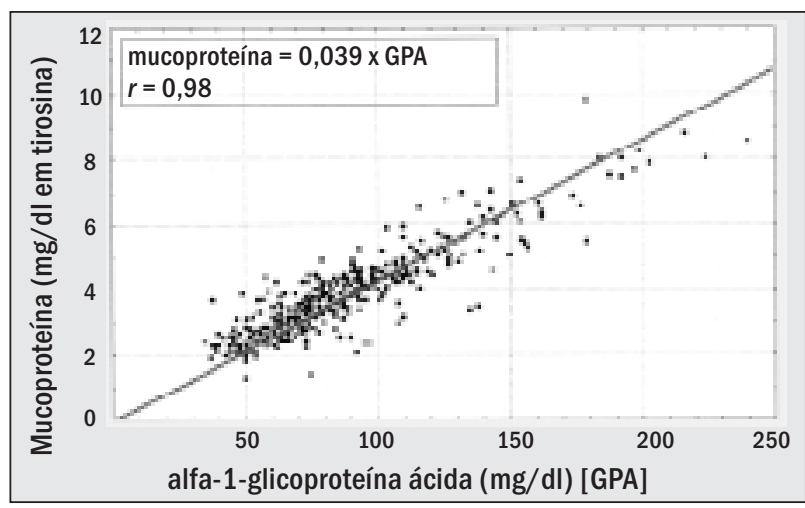

Figura 3 - Análise de regressão linear entre alfa-1-glicoproteína ácida (GPA) e mucoproteína expressa em tirosina quando o intercepto foi ajustado a zero. 0 coeficiente de correlação (r) e a equação de regressão encontram-se em destaque

samento, a qualidade do papel de filtro utilizado é determinante, bem como a concentração do ácido fosfotúngstico e a força de centrifugação empregadas na precipitação e sedimentação da mucoproteína. Na colorimetria, o cromógeno é dependente do $\mathrm{pH}$ alcalino do meio e, por conseguinte, da remoção do ácido utilizado na fase anterior. As hidroxilas fenólicas dos resíduos de tirosina presentes no meio são responsáveis pela geração do produto colorido, sendo que a própria tirosina é utilizada no sistema de calibração, por não existir um padrão de muco- 
proteína $(10,11)$. A metodologia descrita por Winzler, portanto, propicia a introdução de artefatos técnicos em todas as etapas analíticas.

A quantificação da GPA utilizando anticorpos específicos está disponível para uso nos laboratórios clínicos há cerca de três décadas, e vários laboratórios introduziram este ensaio em suas rotinas em substituição à quantificação da Muco. Entre as vantagens dessa metodologia, podem ser citadas: especificidade, precisão e capacidade de automação do procedimento. Os reagentes comerciais disponibilizam calibradores e controles, possibilitando resultados confiáveis.

Os ensaios de imprecisão (reprodutibilidade) descritos na Tabela mostram que o coeficiente de variação interensaio de Muco foi 4,5 vezes maior do que o obtido para a determinação de GPA $(23,4 \%$ e $5,2 \%$, respectivamente). Soros-controles comercializados pelo Programa de Excelência de Laboratórios Médicos/Sociedade Brasileira de Patologia Clínica (PELM/SBPC) e pelo Programa Nacional de Controle de Qualidade/Sociedade Brasileira de Análises Clínicas (PNCQ/SBAC) reportam em suas bulas valores de coeficiente de variação superiores a $30 \%$ para a determinação de Muco, em concordância com os valores encontrados. Variabilidade analítica tão elevada quanto a observada na quantificação da Muco coloca este ensaio como semiquantitativo, minimizando sua utilidade clínica, em especial quando comparada com a performance da GPA. Marteau et al. (7) e Verme et al. (16) relatam, respectivamente, valores de $4,25 \%$ e $6,6 \%$ de coeficiente de variação interensaio para GPA em sistemas automatizados, semelhantes aos obtidos neste estudo $(5,2 \%)$.

As análises de regressão mostradas nas Figuras 2 e 3 resultaram nas equações: Muco ( $\mathrm{mg} / \mathrm{dl}$ em tirosina) $=$ $0,031 \times \mathrm{GPA}(\mathrm{mg} / \mathrm{dl})+0,8 ;$ e, quando o intercepto foi ajustado a zero, Muco (mg/dl em tirosina) = 0,039 x GPA $(\mathrm{mg} / \mathrm{dl})$, com coeficientes de correlação $(r)$, respectivamente, de 0,91 e 0,98. A elevada correlação entre os ensaios era esperada, uma vez que a GPA é o componente majoritário da Muco. A equação de regressão permite estimar a Muco através da GPA, sendo que o inverso não é possível, devido à alta variabilidade analítica da Muco, que, se utilizada como discriminante, possibilitaria elevada incerteza na estimativa. Santos e Pereira (13) reportaram $28,7 \%$ de incompatibilidade entre os resultados de Muco e GPA, apontando a susceptibilidade a erros analíticos na determinação de Muco como justificativa para o achado.

A equação simplificada, com intercepto em zero, Muco = 0,039 x GPA é semelhante à sugerida por Mitre (9), o qual propõe que a razão GPA/Muco é aproximadamente igual a 25, ou seja, multiplicar a GPA por 0,04 estima o valor da Muco.

Em resumo, a variabilidade analítica elevada da quantificação da mucoproteína pelo método de Winzler recomenda que este ensaio seja substituído pela dosagem da alfa-1-glicoproteína ácida. Em situações nas quais o laboratório seja compelido a liberar o resultado de mucoproteína, ou necessite comparar resultados desta com os de alfa-1-glicoproteína ácida, recomendamos quantificar a GPA e estimar a mucoproteína por uma das equações de regressão apresentadas neste trabalho, em especial $0,039 \times \mathrm{GPA}=$ Muco, desde que o procedimento analítico empregado na determinação da GPA apresente o mesmo desempenho do método utilizado neste estudo.

\section{Agradecimentos}

Os autores agradecem ao Laboratório Frischmann Aisengart pela execução dos ensaios e pelo suporte para a realização deste trabalho.

\section{Referências}

I. Ballou, S.P. et al. Quantitative and qualitative alterations of acutephase proteins in healthy elderly persons. Age Ageing, 25(3): 224-38, 1996.

2. Bishop, M.L.; Duben-Engelkirk, J.L. \& Fody, E.P. Clinical chemistry: principles, procedures, correlations. 4.ed. Filadélfia: Lippincott, 2000, p. $165-6$

3. Bornstein, I.; Wagh, P.V. \& Winzler, R.J. The structure of a glycopeptide from human orosomucoid (alpha-I-acid glycoprotein).J. Biol. Chem., 244(4): 658-65, 1969.
4. Burtis, C.A. \& Ashwood, E.R. (eds.) Tietz textbook of clinical chemistry. 3.ed. Filadélfia: Saunders, 1999.

5. Henry, R.J:; Cannon, D.C. \& Winkelman, J.W. Quimica clinica: bases y tecnicas. 2.ed. Barcelona: Editorial JIMS, 1980, v. I, p. 460-70.

6. Hornig, M. et al. Positive and negative acute phase proteins in affective subtypes. J. Affect. Disord., 49( I): 9-18, 1998.

7. Marteau, F. et al. Immunoturbidimetric assay for alpha I-acid glycoprotein in serum with a centrifugal analyzer.Clin. Chem. 3I (6): 873-4, 1985. 
8. Miholic, J. et al. Early prediction of deep sternal wound infection after heart operation by alpha- I acid glycoprotein and Creactive protein measurements. Ann. Thorac. Surg., 42(4): 429-33, 1986.

9. Mitre, L. Relevância clínica e laboratorial da alfa- I-glicoproteína ácida. Laes \& Haes, I03: 94-6, 1996.

10. Moura, R.A.A. et al. Técnicas de laboratório. Rio de Janeiro: Atheneu, 1977, p. 124-7.

I I. Nogueira, D.M. et al. Métodos de bioquímica clínica: técnica e interpretação. São Paulo: Pancast, 1990, p. 263-6.

12. Ritchie, R.F. et al. Reference distributions for the positive acute phase serum proteins, alpha-I-acid glycoprotein (orosomucoid), alpha- I-antitrypsin, and haptoglobin: a practical, simple, and clinically relevant approach in a large cohort.J. Clin. Lab. Anal., I 4(6): 284-92, 2000.
I 3. Santos, H.B. \& Pereira, J.V. Correlação entre as determinações de alfa-I-glicoproteína ácida e mucoproteínas. Roche in News, 2: 8-9, 2000.

14. Shiyan, S.D. \& Bovin, N.V. Carbohydrate composition and immunomodulatory activity of different glycoforms of alpha- I-acid glycoprotein. Glycoconj. J., I 4(5): 631-8, 1997.

15. Statsoft, Inc. Statistica for Windows (Computer program manual). Tulsa, 1996.

16.Verme, C.N.; Ludden,T.M. \& Harris, S.C. Immunoassay of alpha I-acid glycoprotein in the Cobas Bio centrifugal analyzer. Clin. Chem., 34(I I): 2316-20, 1988.

17. Winzler, R.J. Methods of biochemical analysis. Nova York: Interscience, 1955, v. 2, p. 245.

18. Winzler, R.J. The plasma proteins. Nova York: Academic Press, 1960, v. I, p. 309 